\title{
Influence of oleic acid in different solvent media on BRL 3A cell growth and viability
}

\author{
Runqi Liu, Wei Yang, Cheng Xia, Yuanyuan Chen, Sansi Gao, Zhihao Dong, Baoyin Huang, \\ Ruirui Li, Ping He and Chuang $\mathrm{Xu}^{\bowtie}$
}

College of Animal Science and Veterinary Medicine, Heilongjiang Bayi Agricultural University, Daqing, Heilongjiang, China

\begin{abstract}
Oleic acid (OA) is widely used in pathology studies of hepatocellular lipid deposition. Identifying the effects of different solvents on OA-induced liver lipid deposition would be beneficial for studies on hepatocytes. We treated BRL $3 A$ cells with OA dissolved in different solvents. After $12 \mathrm{~h}$ incubation, cell viability was assessed using MTT assays. Reactive oxygen species (ROS), triglyceride (TG) and total cholesterol (TC) counts, and the expression level of glucose regulated protein (GRP78), sterol regulatory element binding protein (SREBP-1C) and fatty acid synthase (FAS) were analyzed. Water, PBS and DMSO were disadvantageous to the dissolution of $O A$ and did not cause an $O A$-induced response in hepatocytes. In the alcohol+OA-treated cells, the severe ER stress, oxidative stress and cellular fat deposition were significantly increased. BSA promoted cell growth and the cells treated with $1.2 \%$ BSA+OA showed a lower grade TG and endoplasmic reticulum stress compared with $\mathrm{KOH}+\mathrm{OA}$ and alcohol+OA treatments. $\mathrm{KOH}$ had no significant influence on BRL $3 A$ cells viability. When treated with $\mathrm{OA}$ dissolved in $\mathrm{KOH}, \mathrm{BRL} 3 \mathrm{~A}$ cells showed a typical hepatocyte damage. $\mathrm{KOH}$ was considered the suitable choice for an OA solvent for BRL $3 A$ cells in hepatic lipidosis research.
\end{abstract}

Key words: oleic acid; non-alcoholic fatty liver disease; liver lipid deposition

Received: 23 January, 2018; revised: 13 June, 2018; accepted: 19 June, 2018; available on-line: 15 September, 2018

e-mail: xuchuang7175@163.com

Abbreviations: BSA, bovine serum albumin; DMSO, dimethyl sulfoxide; FAS, fatty acid synthase; GRP78, glucose regulated protein 78; $\mathrm{H}_{2} \mathrm{O}$, distilled water; $\mathrm{KOH}$, potassium hydroxide; $\mathrm{OA}$, oleic acid; PBS, phosphate-buffered saline; ROS, reactive oxygen species; SREBP-1C, sterol regulatory element binding protein 1c; TC, total cholestero; TG, triglyceride

\section{INTRODUCTION}

Non-alcoholic fatty liver disease (NAFLD) is one of the types of fatty liver which occurs when fat is deposited in the liver due to the causes other than excessive alcohol use. In most of the cases of NAFLD a metabolic syndrome is also present (Xu et al., 2016a). A high-fat diet is the major pathogenesis factor as the most dietary fat sources contain abundant free fatty acids (FFAs). Liver and adipose tissue are the major organs of lipid metabolism and take part in modulating lipid oxidative capacity and energy demands (Xu et al., 2015). A surplus of FFAs in non-adipose cells, especially hepatocytes, may activate deleterious pathways leading to a cell dysfunction (Xu et al., 2016b). Furthermore, high levels of FFAs could contribute to mitochondrial dysfunction on the level of production of reactive oxygen species and activation of endoplasmic reticulum stress-associated mechanisms (Perla et al., 2017). Oleic acid (OA) is a unique unsaturated fatty acid which plays a key role in cellular activity, metabolism, and nuclear events (Imai et al., 2003). It is synthesized de novo from palmitic acid or dietary palmitic acid by palmitoyl-CoA elongation, or from stearic acid by stearoyl-CoA desaturation (Cinti et al., 1992). OA is widely used in pathological studies of hepatic lipidosis. In in vitro studies, the various solvents for dissolving OA are used (Cairns et al., 2017, Li et al., 2015, Weng et al., 2017), but the effect of these solvents on hepatocytes are unclear, thus, identifying the effects of OA in different solvents on hepatocytes would be beneficial. In this study, OA was dissolved in distilled water $\left(\mathrm{H}_{2} \mathrm{O}\right)$, potassium hydroxide $(\mathrm{KOH})$, alcohol, phosphate-buffered saline (PBS), bovine serum albumin (BSA), and dimethyl sulfoxide (DMSO) to evaluate the effect of different solvents on OA-induced hepatic lipidosis, viability, oxidative stress and endoplasmic reticulum stress.

\section{MATERIALS AND METHODS}

Cell cultures and treatment. The BRL3A rat liver cell line was purchased from Stem Cell Bank, Chinese Academy of Sciences (Shanghai, China) and cultured in DMEM (GIBCO, Life Technologies, USA) containing 10\% FBS (GIBCO, Life Technologies) with 1\% Penicillin-Streptomycin Solution (Solarbio Life Sciences, Beijing, China) in a humidified incubator at $37^{\circ} \mathrm{C}$ with $5 \% \mathrm{CO}_{2}$. Stock solutions of $158.5 \mu \mathrm{OA}$ were prepared in $10 \mathrm{ml}$ of $0.1 \mathrm{mM} \mathrm{KOH}$ (Liu et al., 2014, Wang et al., 2015), 0.1 mM PBS, alcohol (absolute ethyl ethanol; Lagrutta et al., 2017, Chen et al., 2014, Liao et al., 2014), BSA (0.4\%, $0.8 \%, 1.2 \%$ ) (Moravcova et al., 2015, Seo et al., 2014) and DMSO $(0.1 \%, 0.4 \%, 0.8 \%$ ) (Rogue et al., 2014, Zhang et al., 2004), respectively, and diluted in DMEM culture medium to a final concentration of $\mathrm{OA}$ at $1.2 \mathrm{mM}$. About $5 \times 10^{4}$ BRL $3 \mathrm{~A}$ cells per well were seeded on the six-well culture plates and treated with different solvents and $\mathrm{OA}$ in different solvents. The cells were harvested after 12 hours.

Assessment of BRL 3A cell viability. BRL 3A cells were seeded in 96-well culture plates at about 3000 cells per well. To determine cell viability, cells were treated for $6,12,24$ or $48 \mathrm{~h}$. A final concentration of $5 \mathrm{mg} /$ $\mathrm{ml}$ methylthiazolyldiphenyl-tetrazolium bromide (MT'T) was added for the last $4 \mathrm{~h}$ of the incubation time. Then the medium was removed carefully and added to $150 \mu \mathrm{l}$ DMSO for $0.5 \mathrm{~h}$ and which was next used for cell viability analysis using spectrophotometer at $492 \mathrm{~nm}$. Four independent experiments were performed for each group. 
Table 1. Primer sets used in PCR

\begin{tabular}{lll}
\hline Gene & Forward $\left(5^{\prime}-3^{\prime}\right)$ & Reverse $\left(5^{\prime}-3^{\prime}\right)$ \\
\hline Tbp & ACTCCTGCCACACCAGCC & GGTCAAGTTACAGCCAAGATTCA \\
\hdashline Grp-78 & AACCCAGATGAGGCTGTAGCATA & CACAGTGTTCCTCGGAATCAGTT \\
\hdashline Srebp-1c & GACGACGGAGCCATGGATT & GGGAAGTCACTGTCTTGGTTGTT \\
\hdashline Fas & CTATTGTGGACGGAGGTATC & TGCTGTAGCCCAGAAGAG \\
\hline
\end{tabular}

USA). RNA was reverse transcribed into cDNA using high-capacity cDNA reverse transcription kits (Invitrogen, Switzerland) according to the manufacturer's instructions. mRNA levels for GRP78, SREBP-1C and FAS were analyzed using Applied Biosystems 7300 real-time polymerase chain reaction (PCR) system and SYBR Premix Ex TaqI (TaKaRa, Dalian, China). Primers were designed using Primer Express

TG and TC concentration determination. After the incubation, the cells were lysed by brief sonication in $2 \%$ Triton X-100 in an ice bath. The lysates were centrifuged at $10000 \times \mathrm{g}$ at $4^{\circ} \mathrm{C}$ for $10 \mathrm{~min}$. The supernatants were collected for TG and TC analysis using commercial enzymatic kits (Pulilai Biotechnology, Beijing, China). Four independent experiments were performed for each group.

Measurement of ROS production. After collecting cells according to ROS kit (Applygen, Beijing, China) instructions, cells were treated with $10 \mu \mathrm{M}$ DCFH-DA in PBS for $40 \mathrm{~min}$ at $37^{\circ} \mathrm{C}$ and photographed using a fluorescence microscope for ROS analysis.

Lipid synthesis activity and endoplasmic reticulum stress determination. Expression of sterol regulatory element binding protein (SREBP-1C) and fatty acid synthase (FAS) were used for determination of lipid synthesis activity of the cells, and expression of glucose regulated protein (GRP78) was used for endoplasmic reticulum stress determination. Total RNA was extracted using TRIZOL reagent (Invitrogen, software from Applied Biosystems and synthesized (Table 1).

Statistical analysis. Data are provided as means \pm S.E.M. All data were tested for significance using unpaired Student t-test or ANOVA. Only results with $p<0.05$ were considered statistically significant.

\section{RESULTS}

\section{Cell viability assays}

For a $12 \mathrm{~h}$ stimulation, the surviving fractions of the $0.8 \%$ BSA+OA, $1.2 \%$ BSA and the $1.2 \%$ $\mathrm{BSA}+\mathrm{OA}$ treated cells were significantly higher than in the control groups $(p<0.05$, Table 2$)$. Also for a $24 \mathrm{~h}$ stimulation, the survival rates of the $0.8 \% \mathrm{BSA}$ group, the $0.8 \% \mathrm{BSA}+\mathrm{OA}$ group, the $1.2 \% \mathrm{BSA}$ group and the $1.2 \% \mathrm{BSA}+\mathrm{OA}$ group, were significantly higher than in the control groups $(p<0.05)$. On

Table 2. Cell viability assays in BRL $3 A$ cells with OA in different solvents

\begin{tabular}{|c|c|c|c|c|c|c|}
\hline & \multicolumn{2}{|c|}{$6 \mathrm{~h}$} & \multicolumn{2}{|c|}{$12 \mathrm{~h}$} & \multicolumn{2}{|c|}{$24 \mathrm{~h}$} \\
\hline & OD Count & Fraction Surviving & OD Count & Fraction Surviving & OD Count & Fraction Surviving \\
\hline Control & $0.673 \pm 0.02$ & $100 \%$ & $0.697 \pm 0.015$ & $100 \%$ & $0.655 \pm 0.001$ & $100 \%$ \\
\hline $\mathrm{H}_{2} \mathrm{O}$ & $0.653 \pm 0.003$ & $96.93 \%$ & $0.663 \pm 0.038$ & $95.17 \%$ & $0.626 \pm 0.02$ & $95.57 \%$ \\
\hline $\mathrm{H} 2 \mathrm{O}+\mathrm{OA}$ & $0.622 \pm 0.021$ & $98.33 \%$ & $0.680 \pm 0.016$ & $97.56 \%$ & $0.727 \pm 0.014$ & $101.00 \%$ \\
\hline $\mathrm{KOH}$ & $0.673 \pm 0.04$ & $99.90 \%$ & $0.695 \pm 0.007$ & $99.71 \%$ & $0.639 \pm 0.03$ & $97.61 \%$ \\
\hline $\mathrm{KOH}+\mathrm{OA}$ & $0.696 \pm 0.043$ & $103.32 \%$ & $0.712 \pm 0.008$ & $102.15 \%$ & $0.709 \pm 0.091$ & $108.35 \%$ \\
\hline Alcohol & $0.607 \pm 0.03$ & $90.10 \%$ & $0.644 \pm 0.005$ & $92.35 \%$ & $0.541 \pm 0.02^{*}$ & $82.59 \%$ \\
\hline Alcohol+OA & $0.556 \pm 0.012$ & $92.57 \%$ & $0.671 \pm 0.030$ & $96.27 \%$ & $0.530 \pm 0.022^{*}$ & $89.96 \%$ \\
\hline PBS & $0.644 \pm 0.007$ & $95.59 \%$ & $0.650 \pm 0.007$ & $93.26 \%$ & $0.617 \pm 0.005$ & $94.20 \%$ \\
\hline $\mathrm{PBS}+\mathrm{OA}$ & $0.697 \pm 0.018$ & $103.47 \%$ & $0.641 \pm 0.053$ & $91.97 \%$ & $0.607 \pm 0.004$ & $92.63 \%$ \\
\hline $0.4 \%$ BSA & $0.611 \pm 0.01$ & $95.69 \%$ & $0.728 \pm 0.051$ & $104.50 \%$ & $0.668 \pm 0.03$ & $101.99 \%$ \\
\hline $0.4 \% \mathrm{BSA}+\mathrm{OA}$ & $0.701 \pm 0.023$ & $104.06 \%$ & $0.745 \pm 0.063$ & $106.89 \%$ & $0.731 \pm 0.013$ & $111.61 \%$ \\
\hline $0.8 \% \mathrm{BSA}$ & $0.651 \pm 0.03$ & $96.68 \%$ & $0.782 \pm 0.017$ & $112.15 \%$ & $0.759 \pm 0.01 *$ & $115.94 \%$ \\
\hline $0.8 \% \mathrm{BSA}+\mathrm{OA}$ & $0.764 \pm 0.018$ & $113.51 \%$ & $0.795 \pm 0.026^{*}$ & $114.06 \%$ & $0.776 \pm 0.023 *$ & $118.58 \%$ \\
\hline $1.2 \% \mathrm{BSA}$ & $0.756 \pm 0.02$ & $112.33 \%$ & $0.869 \pm 0.063^{*}$ & $124.73 \%$ & $0.997 \pm 0.08^{*}$ & $152.29 \%$ \\
\hline $1.2 \% \mathrm{BSA}+\mathrm{OA}$ & $0.690 \pm 0.041$ & $102.48 \%$ & $0.829 \pm 0.012^{*}$ & $118.94 \%$ & $0.791 \pm 0.018 *$ & $120.88 \%$ \\
\hline $0.1 \%$ DMSO & $0.632 \pm 0.01$ & $93.91 \%$ & $0.674 \pm 0.002$ & $96.75 \%$ & $0.625 \pm 0.07$ & $95.42 \%$ \\
\hline $0.1 \% \mathrm{DMSO}+\mathrm{OA}$ & $0.657 \pm 0.015$ & $97.52 \%$ & $0.632 \pm 0.108$ & $94.70 \%$ & $0.527 \pm 0.047$ & $95.45 \%$ \\
\hline $0.4 \%$ DMSO & $0.638 \pm 0.02$ & $94.75 \%$ & $0.686 \pm 0.043$ & $98.37 \%$ & $0.636 \pm 0.01$ & $97.20 \%$ \\
\hline $0.4 \% \mathrm{DMSO}+\mathrm{OA}$ & $0.612 \pm 0.077$ & $90.89 \%$ & $0.782 \pm 0.039$ & $90.67 \%$ & $0.627 \pm 0.032$ & $95.82 \%$ \\
\hline $0.8 \%$ DMSO & $0.595 \pm 0.01$ & $88.32 \%$ & $0.604 \pm 0.045$ & $86.66 \%$ & $0.517 \pm 0.03^{*}$ & $78.93 \%$ \\
\hline $0.8 \%$ DMSO+OA & $0.488 \pm 0.018^{*}$ & $82.48 \%$ & $0.604 \pm 0.038$ & $86.66 \%$ & $0.517 \pm 0.014^{*}$ & $78.92 \%$ \\
\hline
\end{tabular}

Fraction Surviving: OD of treated samples/OD of control samples* 100 . Statistical significance: ${ }^{*} p<0.05 v s$. control at the same time point; ${ }^{* *} p<0.01$ vs. control at the same time point. 


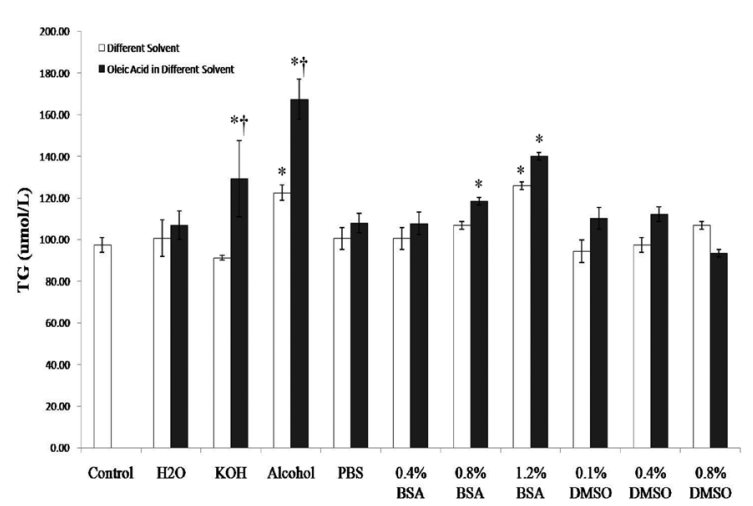

b

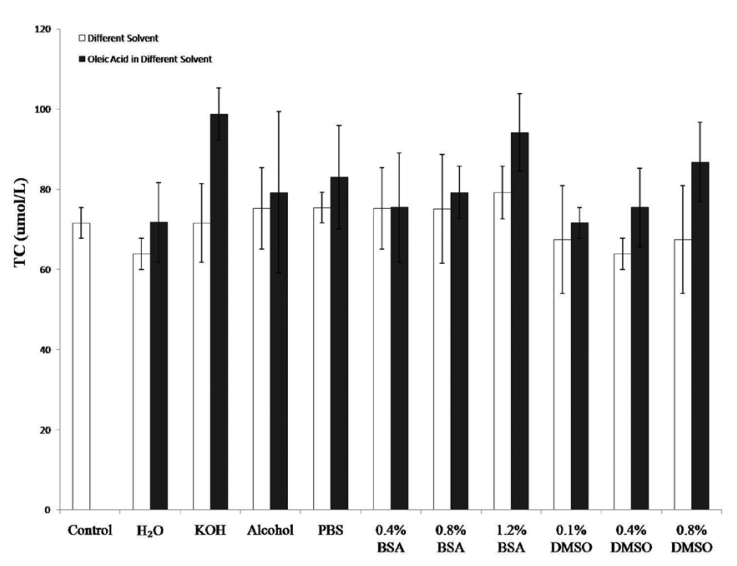

Figure 1. TG and TC counts in BRL $3 A$ cells treated with OA in different solvents or solvents only

TG and TC counts in BRL 3A cell which treated with solvent or OA in different solvents for $12 \mathrm{~h}$. (a) BRL 3Acells were seeded in sixwell culture plates and treated with $\mathrm{OA}$ in different solvents or the solvents only for $12 \mathrm{~h}$. The supernatants were collected for TG analysis using commercial enzymatic kits and a microplate multifunction reader. (b) BRL 3 Acells were seeded in six-well culture plates and treated with with $\mathrm{OA}$ in different solvents or the solvents only for $12 \mathrm{~h}$. The supernatants were collected for TC analysis using commercial enzymatic kits and a microplate multifunction reader. *indicates a significant difference $(p<0.05)$ between solvent and control groups; $\dagger$ indicates a significant difference $(p<0.05)$ between solvent+OA and corresponding solvent group; neither $*$, nor $\dagger$, indicates no significant difference $(p>0.05)$.

the other hand, the surviving fractions in the alcohol group, alcohol+OA group, $0.8 \%$ DMSO group and the $0.8 \%$ DMSO+OA group were significantly lower than in the control groups $(p<0.05)$ after 24 hour stimulation.

\section{Effect of OA in different solvents on BRL-3A induction of TG and TC counts}

TG counts for the alcohol, 1.2\% BSA, $\mathrm{KOH}+\mathrm{OA}$, alcohol+OA, $\quad 0.8 \% \quad \mathrm{BSA}+\mathrm{OA}$ and $1.2 \% \quad \mathrm{BSA}+\mathrm{OA}$ groups were significantly higher than in the control group $(p<0.05)$ (Fig. 1). TG count for the $\mathrm{KOH}+\mathrm{OA}$ group, alcohol+OA group and $1.2 \% \mathrm{BSA}+\mathrm{OA}$ group were significantly higher than in the corresponding solvents group. No significant difference was seen in TC counts among different solvent groups and normal control groups (Fig. 1).

\section{Intracellular ROS}

As showed in Fig. 2, the observations were further corroborated by an increased ROS production

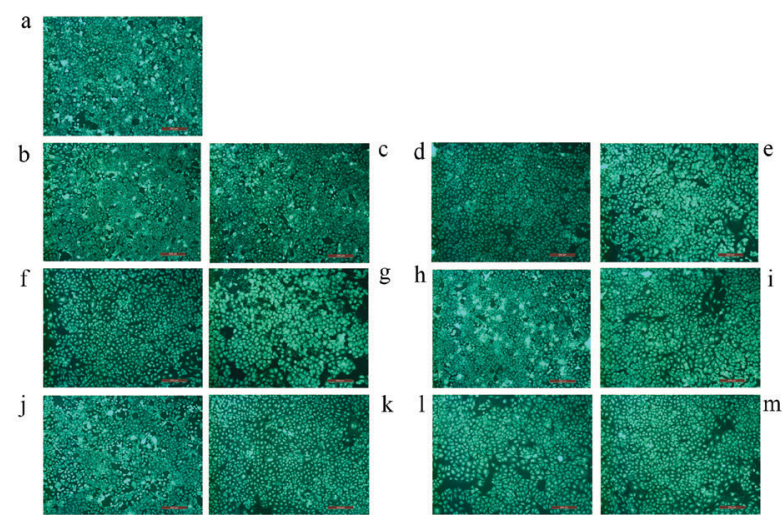

Figure 2. ROS analysis using a fluorescence microscope. The intensity of fluorescence corresponds to the amount of ROS. The stronger the fluorescence intensity in the picture, the more ROS in the BRL $3 \mathrm{~A}$ cells. The weaker the fluorescence intensity in the picture, the less ROS in the BRL 3 A cells. Figures $\mathbf{a}, \mathbf{b}, \mathbf{c}, \mathbf{d}$, $\mathbf{e}, \mathbf{f}, \mathbf{g}, \mathbf{h}, \mathbf{i}, \mathbf{j}, \mathbf{k}, \mathbf{I}$ and $\mathbf{m}$ correspond to control $\mathrm{H} 2 \mathrm{O}, \mathrm{H} 2 \mathrm{O}+\mathrm{OA}$, $\mathrm{KOH}, \mathrm{KOH}+\mathrm{OA}$, Alcohol, Alcohol+OA, PBS, PBS+OA, BSA, BSA+OA, DMSO and DMSO+OA groups, respectively.

in the alcohol and DMSO groups. ROS production in the $\mathrm{KOH}+\mathrm{OA}$ and alcohol+OA groups was significantly increased compared to the corresponding solvent groups. ROS production in the $\mathrm{PBS}+\mathrm{OA}, \mathrm{BSA}+\mathrm{OA}$ and $\mathrm{DMSO}+\mathrm{OA}$ groups was increased compared to the corresponding solvent groups. No significant difference in ROS production was observed between $\mathrm{H}_{2} \mathrm{O}+\mathrm{OA}$ and $\mathrm{H}_{2} \mathrm{O}$ groups.

\section{Effect of OA in different solvents on GRP78, SREBP-1C and FAS MRNA in BRL $3 A$ cells}

GRP78 mRNA levels were significantly higher in the alcohol, $\mathrm{KOH}+\mathrm{OA}$, alcohol+OA and $1.2 \% \mathrm{BSA}+\mathrm{OA}$ groups compared to the control groups $(p<0.05$, Fig. 3). GRP78 mRNA was significantly higher in the $\mathrm{KOH}+\mathrm{OA}$ and alcohol+OA groups compared to corresponding solvent groups $(p<0.05)$. Other groups had higher GRP78 expression than the control groups, but the differences were not significant.

SREBP-1C mRNA levels were significantly lower in the alcohol, $\mathrm{KOH}+\mathrm{OA}$, alcohol+OA, 1.2\% BSA+OA, $0.8 \% \mathrm{BSA}+\mathrm{OA}$ and $0.8 \% \mathrm{DMSO}+\mathrm{OA}$ groups compared to the control group $(p<0.05)$. SREBP-1C mRNA in the $\mathrm{KOH}+\mathrm{OA}, 0.8 \%$ DMSO and $0.8 \%$ BSA groups was significantly lower than in the corresponding solvent groups $(p<0.05)$. FAS mRNA levels were significantly lower in the $\mathrm{H}_{2} \mathrm{O}+\mathrm{OA}, \mathrm{KOH}+\mathrm{OA}$, alcohol+OA, $0.4 \%$ BSA, $0.8 \%$ DMSO and $0.8 \%$ DMSO+OA groups compared to the control group $(\phi<0.05)$. FAS mRNA levels in the $\mathrm{KOH}+\mathrm{OA}$ groups were significantly lower than in the corresponding solvent groups $(p<0.05)$.

\section{DISCUSSION}

NAFLD becomes increasingly prevalent due to the worldwide obesity epidemic and currently affects about one billion people worldwide (Webster, 2017). Steatosis is the earliest and most common stage of NAFLD and is often referred to as the "first hit". During this stage, FFAs accumulate in the cells, which is followed by the production of ROS and lipid peroxidation. It has been proposed that the lipotoxicity of FFAs increases the liver's vulnerability to a "second hit" involving environmental and/or genetic factors, which ultimately can lead 
a

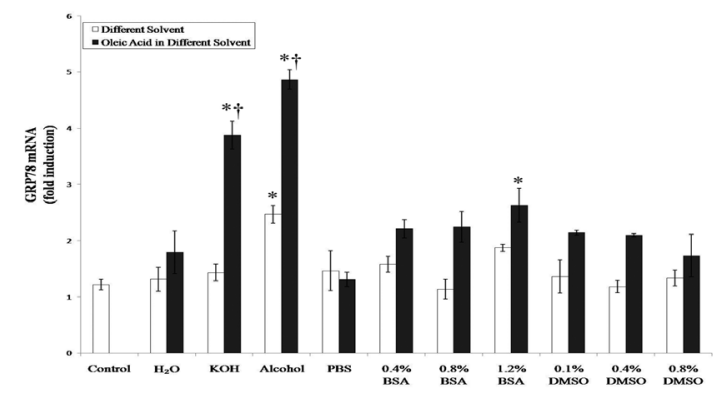

$\mathrm{b}$

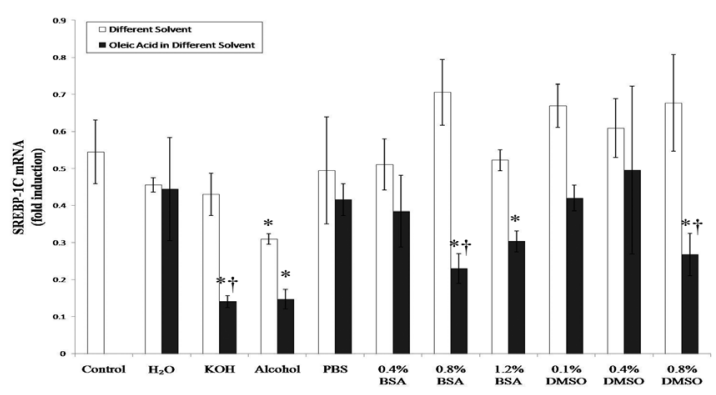

c

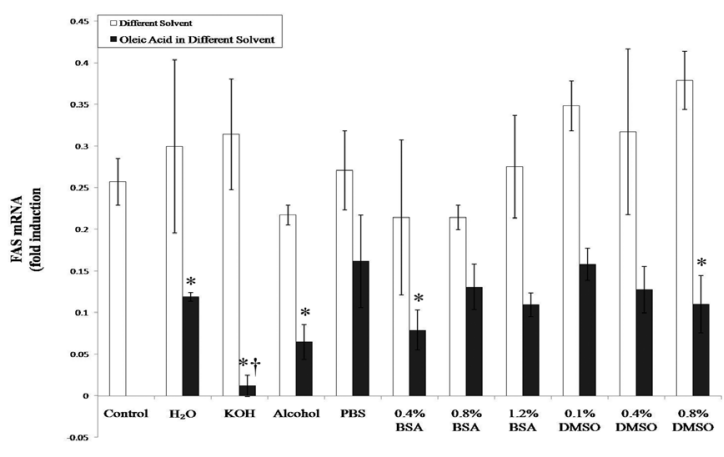

Figure 3. GRP78, SREBP-1C and FAS mRNA counts in BRL 3A cells

Figures $\mathbf{a}, \mathbf{b}$ and $\mathbf{c}$ correspond to GRP78, SREBP-1C and FAS mRNA counts, respectively. ${ }^{*}$ indicates a significant difference $(p<0.05)$ between solvent and control groups; $\dagger$ indicates a significant difference $(p<0.05)$ between solvent+OA and corresponding solvent groups; neither *nor $t$, indicates no significant difference $(p>0.05)$.

to end-stage liver disease (Periasamy et al., 2014). Growing evidence suggests that endoplasmic reticulum (ER) stress may link saturated fatty acids to NAFLD (Mota et al., 2016). ER stress causes the activation of the unfolded protein response (UPR) and the sterol regulatory element-binding protein (SREBP) pathway (Zhao \& Ackerman 2006). Once activated, the UPR increases the expression of intraluminal ER chaperones, especially GRP78, in order to cope with the accumulation of unfolded or misfolded proteins. Hence GRP78 is a marker of endoplasmic reticulum stress (Moslehi et al., 2017). In contrast, SREBP-1 acts as a transcription factor that regulates the genes that control the synthesis of fatty acids and the cellular uptake of lipoproteins (Zhang et al., 2014). SREBP-1c regulates hepatic lipogenic gene transcription and insulin-induced lipogenesis, and its target genes include FAS, acetyl coenzyme A carboxylase (ACC), and low-density lipoprotein receptor (Liao et al., 2010). SREBP-1c is involved in almost all hepatic fatty acid and TG synthesis, gene transcription and TG synthesis, gene transcription and transformation. FAS is a fatty acid synthase. Both SREBP-1C and FAS are regulators of de novo fat synthesis (Zhou et al., 2017).

In previous work (Muller et al., 2010) have demonstrated that non-esterified fatty acid (NEFA) caused NAFLD-like changes within hepatocytes, including lipid accumulation, oxidative stress and cell death (Muller et al., 2012). High concentrations of NEFAs can induce oxidative stress in hepatocytes by increasing the levels of ROS (Shi et al., 2015; Song et al., 2016; Du et al., 2017). To study the pathogenesis mechanism of NAFLD in vitro, fatty acids were used to induce hepatic lipid deposition. But the effects of the use of the different solvents for fatty acids remained unclear. Alcohol has been used in many studies (Lagrutta et al., 2017; Chen et al., 2014; Liao et al., 2014) as a solvent of oleic acid. Some experiments have proved that low concentration of DMSO (Rogue et al., 2014; Zhang et al., 2004) exerted little damage to the cells, so we chose $0.8 \% \quad 0.4 \% \quad 0.1 \%$ concentration of DMSO for our experimentation. $\mathrm{KOH}$ was chosen as the solvent for oleic acid because many NEFA models of non-alcoholic fatty liver were dissolved in $\mathrm{KOH}$ (Liu et al., 2014; Wang et al., 2015). For an overall evaluation of the influence of oleic acid in different solvent media on the cells, PBS and $\mathrm{H}_{2} \mathrm{O}$ were also used as solvents in this research. In the present study, BRL $3 \mathrm{~A}$ cells were treated with $\mathrm{OA}$ in different solvents to explore the influence of these solvents on hepatic lipid deposition. We screened the mild solvents of oleic acid to see the effects of different solvents on cell viability, toxicity and the degree of oxidative stress and hepatocyte lipid deposition. It was found that the $\mathrm{OA}$ dissolved in $\mathrm{H}_{2} \mathrm{O}$ and PBS had no significant effect on hepatocytes' response, which did not differ from the control group,. This was probably because $\mathrm{H}_{2} \mathrm{O}$ and PBS are disadvantageous to the dissolution of OA. Alcohol is commonly used in the study of alcoholic fatty liver disease (Zhu et al., 2014; Zhang et al., 2014). OA dissolves in high concentration of alcohol, but high alcohol concentration is also toxic to the cells, resulting in oxidative and endoplasmic reticulum stress (Caires et al., 2012). In this study, cells treated with alcohol+OA had significantly increased and severe ER stress, oxidative stress and hepatic fat deposition, compared to the other groups. However, as the alcohol also leads to liver injury, it was considered not appropriate as a solvent to the study of fatty acid in fatty liver, but remains suitable for the research on liver cell degeneration. DMSO is a universal solvent routinely used in experimental and biological disciplines. It is often used to solubilize drug molecules that are otherwise poorly soluble at concentrations of a $10 \%(\mathrm{v} / \mathrm{v})$ range (Galvao et al., 2014). In this study we observed that although when the concentration of DMSO is low, it has little effect on the cell, it is cytotoxic at higher DMSO concentration, causing oxidative stress and endoplasmic reticulum stress. The survival rates of the $1.2 \% \mathrm{BSA}$ group and the $1.2 \%$ BSA+OA group were significantly higher than in the control groups. That was probably because BSA can promote cell growth as a nutrient. The cells treated with BSA showed a lower grade TG and endoplasmic reticulum stress compared with $\mathrm{KOH}+\mathrm{OA}$ and Alcohol+OA groups. In addition, 1.2\% BSA+OA treated cells showed a significantly increased fat deposition compared to the control and BSA groups. $\mathrm{KOH}$ was usually used as the solvent for fatty acids (Song et al., 2016). In this study, KOH group had no significant influence on cell viability, lipid deposition and oxidative stress as compared the control group, while $\mathrm{KOH}+\mathrm{OA}$ group exhibited a typical hepatocyte damage. In summa- 
ry, we consider $\mathrm{KOH}$ to be the most suitable choice for an $\mathrm{OA}$ solvent to be used for BRL $3 \mathrm{~A}$ cells.

\section{Confict of interest statement}

The authors have declared that no competing interest exists.

\section{Acknowledgement of Financial Support}

This work was supported by the National Natural Science Foundation of China (31502133); the Natural Science Foundation of Heilongjiang Province of China (C2015043) and the National Program on Key Research Project of China (2016YFD0501206); Personnel Foundation in Heilongjiang Bayi Agricultural University (XYB2015-08)

\section{REFERENCES}

Caires KC, Shima CM, de Avila J, McLean DJ (2012) Acute ethanol exposure affects spermatogonial stem cell homeostasis in pre-pubertal mice. Reprod Toxicol 33: 76-84. doi:10.1016/j.reprotox.2011.12.002

Cairns R, Alvarez-Guaita A, Martinez-Saludes I, Wason SJ, Hanh J, Nagarajan SR, Hosseini-Beheshti E, Monastyrskaya K, Hoy AJ, Buechler C, Enrich C, Rentero C, Grewal T (2017) Role of hepatic Annexin A6 in fatty acid-induced lipid droplet formation. Exp Cell Res. doi:10.1016/j.yexcr.2017.07.015

Chen L, Wang C, Huang S, Gong B, Yu J, Shi Q, Chen G (2014) Effects of individual and multiple fatty acids (palmitate oleate and docosahaexenoic acid) on cell viability and lipid metabolism in LO2 human liver cells. Mol Med Rep 10: 3254-3260. doi:10.3892/ mmr.2014.2579

Cinti DL, Cook L, Nagi MN, Suneja SK (1992) The fatty acid chain elongation system of mammalian endoplasmic reticulum. Prog Lipid Res 31: 1-51

Du X, Shi Z, Peng Z, Zhao C, Zhang Y, Wang Z, Li X, Liu G, Li $\mathrm{X}$ (2017) Acetoacetate induces hepatocytes apoptosis by the ROSmediated MAPKs pathway in ketotic cows. J Cell Physiol 232: 32963308. doi:10.1002/jcp. 25773

Galvao J, Davis B, Tilley M, Normando E, Duchen MR, Cordeiro MF (2014) Unexpected low-dose toxicity of the universal solvent DMSO. FASEB J 28: 1317-1330. doi:10.1096/fj.13-235440

Imai K, Kudo N, Koyama M, Kawashima Y (2003) Effects of dehydroepiandrosterone on oleic acid accumulation in rat liver. Biochem Pharmacol 65: 1583-1591

Lagrutta LC, Montero-Villegas S, Layerenza JP, Sisti MS, Garcia de Bravo MM, Ves-Losada A (2017) Reversible nuclear-lipid-droplet morphology induced by oleic acid: a link to cellular-lipid metabolism. PLoS One 12: e0170608. doi:10.1371/journal.pone.0170608

Li X, Huang W, Gu J, Du X, Lei L, Yuan X, Sun G, Wang Z, Li X, Liu G (2015) SREBP-1c overactivates ROS-mediated hepatic NFkappaB inflammatory pathway in dairy cows with fatty liver. Cell Signal 27: 2099-2109. doi:10.1016/j.cellsig.2015.07.011

Liao CC, Ou TT, Huang HP, Wang CJ (2014) The inhibition of oleic acid induced hepatic lipogenesis and the promotion of lipolysis by caffeic acid via up-regulation of AMP-activated kinase. J Sci Food Agric 94: 1154-1162. doi:10.1002/jsfa.6386

Liao FH, Liou TH, Shieh MJ, Chien YW (2010) Effects of different ratios of monounsaturated and polyunsaturated fatty acids to saturated fatty acids on regulating body fat deposition in hamsters. $\mathrm{Nu}$ trition 26: 811-817. doi:10.1016/j.nut.2009.09.009

Liu L, Li X, Li Y, Guan Y, Song Y, Yin L, Chen H, Lei L, Liu J, Li X, Wang Z, Yang X, Liu G (2014) Effects of nonesterified fatty acids on the synthesis and assembly of very low density lipoprotein in bovine hepatocytes in vitro. J Dairy Sci 97: 1328-1335. doi:10.3168/ jds.2013-6654

Moravcova A, Cervinkova Z, Kucera O, Mezera V, Rychtrmoc D, Lotkova $H$ (2015) The effect of oleic and palmitic acid on induction of steatosis and cytotoxicity on rat hepatocytes in primary culture. Physiol Res 64 (Suppl 5): S627-S636

Moslehi A, Nabavizadeh F, Zekri A, Amiri F (2017) Naltrexone changes the expression of lipid metabolism-related proteins in the endoplasmic reticulum stress induced hepatic steatosis in mice. Clin Exp Pharmacol Physiol 44: 207-212. doi:10.1111/1440-1681.12695
Mota M, Banini BA, Cazanave SC, Sanyal AJ (2016) Molecular mechanisms of lipotoxicity and glucotoxicity in nonalcoholic fatty liver disease. Metabolism 65: 1049-1061. doi:10.1016/j.metabol.2016.02.014

Muller C, Gardemann A, Keilhoff G, Peter D, Wiswedel I, Kropf S, Schild L (2010) Palmitate protects hepatocytes from oxidative stress and triacylglyceride accumulation by stimulation of nitric oxide synthesis in the presence of high glucose and insulin concentration. Free Radic Res 44: 1425-1434. doi:10.3109/10715762.2010.512919

Muller C, Gardemann A, Keilhoff G, Peter D, Wiswedel I, Schild L (2012) Prevention of free fatty acid-induced lipid accumulation oxidative stress and cell death in primary hepatocyte cultures by a Gynostemma pentaphyllum extract. Phytomedicine 19: 395-401. doi:10.1016/j.phymed.2011.12.002

Periasamy S, Chien SP, Chang PC, Hsu DZ, Liu MY (2014) Sesame oil mitigates nutritional steatohepatitis via attenuation of oxidative stress and inflammation: a tale of two-hit hypothesis. I Nutr Biochem 25: 232-240. doi:10.1016/j.jnutbio.2013.10.013

Perla FM, Prelati M, Lavorato M, Visicchio D, Anania C (2017) The role of lipid and lipoprotein metabolism in non-alcoholic fatty liver disease. Children (Basel) 4. doi:10.3390/children4060046

Rogue A, Antherieu S, Vluggens A, Umbdenstock T, Claude N, de la Moureyre-Spire C, Weaver RJ, Guillouzo A (2014) PPAR agonists reduce steatosis in oleic acid-overloaded HepaRG cells. Toxicol Appl Pharmacol 276: 73-81. doi:10.1016/j.taap.2014.02.001

Seo MS, Hong SW, Yeon SH, Kim YM, Um KA, Kim JH, Kim HJ, Chang KC, Park SW (2014) Magnolia officinalis attenuates free fatty acid-induced lipogenesis via AMPK phosphorylation in hepatocytes. I Ethnopharmacol 157: 140-148. doi:10.1016/j.jep.2014.09.031

Zhu S, Ma L, Wu Y, Zhang T, Zhang Q, Rasoul LM, Yunye MG, Zhou LB, Ren G, Li D (2014) FGF21 treatment ameliorates alcoholic fatty liver through activation of AMPK-SIRT1 pathway. Acta Biochim Biophys Sinica 46: 1041-1048. doi.org/10.1093/abbs/gmu097

Shi X, Li D, Deng Q, Li Y, Sun G, Yuan X, Song Y, Wang Z, Li X, Li $X$, Liu G (2015) NEFAs activate the oxidative stress-mediated NFkappaB signaling pathway to induce inflammatory response in calf hepatocytes. I Steroid Biochem Mol Biol 145: 103-112. doi:10.1016/j. jsbmb.2014.10.014

Song Y, Li N, Gu J, Fu S, Peng Z, Zhao C, Zhang Y, Li X, Wang Z, Li X, Liu G (2016) beta-Hydroxybutyrate induces bovine hepatocyte apoptosis via an ROS-p38 signaling pathway. J Dairy Sci 99: 9184 9198. doi:10.3168/jds.2016-11219

Wang J, Zhu X, Wang Z, Yao J, Zhao B, Liu G (2015) Non-esterified fatty acids promote expression and secretion of angiopoietin-like protein 4 in calf hepatocytes cultured in vitro. Mol Cell Biochem 401: 141-146. doi:10.1007/s11010-014-2301-2

Webster NJG (2017) Alternative RNA splicing in the pathogenesis of liver disease. Front Endocrinol (Lausanne) 8: 133. doi:10.3389/fendo. 2017.00133

Weng J, Li W, Jia X, An W (2017) Alleviation of ischemia-reperfusion injury in liver steatosis by augmenter of liver regeneration (ALR) is attributed to antioxidation and preservation of mitochondria. Transplantation. doi:10.1097/TP.0000000000001874

Xu C, Sun LW, Xia C, Zhang HY, Zheng JS, Wang JS (2016a) (1) $\mathrm{H}$-Nuclear magnetic resonance-based plasma metabolic profiling of dairy cows with fatty liver. Asian-Australas J Anim Sci 29: 219-229. doi:10.5713/ajas.15.0439

Xu C, Xu Q, Chen Y, Yang W, Xia C, Yu H, Zhu K, Shen T, Zhang Z (2015) The relationship between Fibroblast Growth Factor-21 and characteristic parameters related to energy balance in dairy cows. BMC Vet Res 11: 271. doi:10.1186/s12917-015-0585-4

Xu C, Xu Q, Chen Y, Yang W, Xia C, Yu H, Zhu K, Shen T, Zhang Z (2016b) FGF-21: promising biomarker for detecting ketosis in dairy cows. Vet Res Commun 40: 49-54. doi:10.1007/s11259-0159650-5

Zhang J, Li Y, Jiang S, Yu H, An W (2014) Enhanced endoplasmic reticulum SERCA activity by overexpression of hepatic stimulator substance gene prevents hepatic cells from ER stress-induced apoptosis. Am J Physiol Cell Physiol 306: C279-C290. doi:10.1152/ ajpcell.00117.2013

Zhang W, Shi Q, Wang X, Xie J, Li S, Wu Q (2004) Effects of different concentrations of DMSO on the growth of gastric carcinoma cells. Chongqing Medicine Magazine 33: 1731-1732

Zhao L, Ackerman SL (2006) Endoplasmic reticulum stress in health and disease. Curr Opin Cell Biol 18: 444-452. doi:10.1016/j. ceb.2006.06.005

Zhou B, Zhou DL, Wei XH, Zhong RY, Xu J, Sun L (2017) Astragaloside IV attenuates free fatty acid-induced ER stress and lipid accumulation in hepatocytes via AMPK activation. Acta Pharmacol Sin 38: 998-1008. doi:10.1038/aps.2016.175 